\title{
PELANGGARAN PRINSIP KERJA SAMA DALAM SUREL LAYANAN PELANGGAN PT BERRYBENKA
}

\author{
M. Wildan ${ }^{1}$,Apriliana Miranti ${ }^{2}$ \\ Dosen Fakultas Sastra, Universitas Pamulang ${ }^{1}$ \\ Alumni Fakultas Sastra, Universitas Pamulang ${ }^{2}$ \\ dosen00278@unpam.ac.id ${ }^{1}$, aprilianamiranti@gmail.com²
}

\begin{abstract}
Abstrak
Era 4.0 dintandai dengan kemajuan teknologi komunikasi. Kegiatan manusia berpindah dari luring ke daring. Bahkan inilah era yang menyintas jarak batas jauh menjadi dekat atau nirjarak. Penelitian ini bertujuan untuk mengetahui pelanggaran prinsip kerja sama pada surel PT Berrybenka. PT Berrybenka salah satu perusahaan retail yang memanfaatkan era kemajuan teknologi komunikasi guna melancarkan aktivitas bisnis daring. PT Berrybenka memanfaatkan surel untuk memberikan layanan kepada para konsumen. Melalui fakta bahasa ditemukan pelanggaran prinsip kerja sama. Untuk membedahnya, tulisan ini menggunakan metode penelitian deskriptif kualitatif. Hasil penelitian menunjukkan bahwa surel PT Berrybenka dalam melayani para konsumen ditemukan pelanggaran prinsip kerja sama. Keempat prinsip kerja sama ini termanipestasikan ke dalam maksim kuantitas, maksim kualitas, maksim relevansi, dan maksim cara.
\end{abstract}

Kata kunci: Prinsip Kerja Sama, Surel, Maksim Kuantitas, Maksim Kualitas, Maksim Relevansi, dan Maksim Cara

\section{Pendahuluan}

Dewasa ini kita berada pada era 4.0. Kemajuan internet menjadi penanda era yang serba daring ini. Bahkan internet menjadi segalanya bagi manusia. Meskipun internet konon dimiliki oleh kalangan tertentu saja, walakin kini sudah telah merambah ke dalam berbagai lapisan usia masyarakat. Bahkan, internet tidak sekadar 
menjadi tatanan hidup baru masyarakat, melainkan internet digunakan untuk menyelesaikan pekerjaan manusia dalam melakukan aktifitas. Di balik sisi positifnya, harus pula diakui bahwa internet terdapat rupa negatifnya. Terlepas dari ini semua, sejatinya internet telah banyak membantu meringankan pola komunikasi manusia, baik yang bersifat umum maupun rahasia.

Menurut Prianto dan Sofia (2010:11) internet sudah masuk ke Indonesia sejak tahun 1988. Hal ini diketahui melalui catatan whois (dibaca who is) ARIN dan APNIC, protokol internet (IP) pertama dari Indonesia adalah UI-NETLAB (192.41.206/24) yang didaftarkan oleh Universitas Indonesia pada 24 Juni 1988, namun awalnya internet tidak populer di Indonesia, hingga kemudian tahun 1990-an internet mulai dikenal, saat itu dikenal dengan paguyuban network.

Seiring kemajuan zaman, internet telah merambah ke dalam aktivitas perdagangan daring. Hal ini sejalan dengan Pritami (dalam Rerung, 2018: 37) pada tahun 2016 lembaga survei MARS (salah satu lembaga riset di Indonesia), menyatakan dari total populasi di Indonesia berjumlah 255,4 juta jiwa, internet baru digunakan oleh 35,4\% (90,5 juta jiwa) dari populasi. Namun, tidak semua melakukan belanja daring, karena hanya $29 \%$ orang (26.3 juta jiwa) pengguna internet yang berbelanja daring. Sisanya memilih tidak berbelanja daring karena banyak faktor, misalnya takut kecewa, takut ditipu, sulit dalam melakukan tahapan pembelanjaannya, dan lain sebagainya. Walau demikian, melalui daring kegiatan manusia dibuat mudah dan praktis dengan memanfaatkan internet, tetapi ternyata muncul juga kebiasaan-kebiasaan baru (dalam hal negatif) yang muncul dari perilaku manusia seperti pelanggaran prinsip kerja sama dalam bertindak tutur yang terdapat dalam surel.

Pelanggaran prinsip kerja sama dalam berujar terjadi karena bertentatangan dengan norma yang diakui secara bersama-sama. Tentu hal ini sejalan dengan yang 
disampaikan oleh Grice bahwa prinsip kerja sama yaitu berikanlah kontribusi Anda dalam percakapan yang sesuai dengan kebutuhan, pada tingkat percakapan tersebut sedang berlangsung, sesuai maksud, dan tujuan di mana Anda terlibat (Nadar, 2013 : 24). Untuk itu, PT Berrybenka sebagai perusahaan retail yang bergerak di bidang penjualan berbasis internet pasti terdapat pelanggaran prinsip-prinsip kerja sama antar konsumen, seperti pelanggaran maksim kuantitas. Boleh jadi seperti yang diungkap oleh (Fauziah, et al. 2018:51) pemicu pelanggaran prinsip kerja sama karena adanya kurang rasa percaya diri dari penutur atau lawan tutur, ingin menunjukkan kelucuan yang membuat suasana monotan dan kurang paham dan tidak tuntasnya di dala memberikan tanggapan saat berdiskusi.

\section{Metode Penelitian}

Dalam tulisan ini penulis menggunakan metode penelitian deskriptif kualitatif. Penggunaannya untuk mendeskripsikan situasi atau kejadian secara tepat dan akurat (Yusuf (2017:63). Adapun identifikasi masalah serta tinjauan pustaka menjadi langkah konkrit dalam mengimplementasikan metode ini (Raco, 2010:98). Sementara sumber data yang digunakan berasal dari percakapan antara pelanggan dan pekerja layanan pelanggan yang terdapat dalam surel layanan pelanggan PT Berrybenka. Adapun periode datanya adalah bulan April 2018. Selanjutnya data diklasifikasi dan direduksi berdasarkan pelanggaran prinsip kerja sama yang di dalamnya terindikasi empat maksim: kuantitas, maksim kualitas, maksim relevansi, dan maksim cara. Selanjutnya, dilakukan penarikan kesimpulan secara berkala atas data terklasifikasi dan tereduksi. 


\section{Pembahasan}

\section{Jenis Implikatur}

Dalam surel PT Berrybenka ditemukan dua jenis implikatur, yaitu: implicated premises dan implicated conclusion.

\section{Implicated Premises}

Data yang menunjukkan implicated premises sebagai berikut.

\section{Data 01}

Pelanggan : “OMG!! Kenapa sampai bisa dicancel lagi. Tolong dicek baik2 dulu apakah pembayaran saya itu melebihi batas waktu atau tidak??? Karena setahu saya, pembayarannya saya lakukan tidak melebihi waktu 24 jam. tolong dicek baik2 email saya yg dikirim pada tgl 19.04.2018 itu. Bukti pembayarannya saya lampirkan juga disitu dan juga sisa pembayarannya pake BENKAPOINT saya yg ada. Dan satu hal lagi, email debora_tina89@yahoo.com BUKANLAH EMAIL SAYA! Tolong dicek baik2 ya, saya kecewa untuk ke2 kalinya, karena orderan saya dicancel bukan karena kesalahan saya, tapi kesalahan dari CS Berrybenka yg tidak membalas email kami pada saat mengirim kan bukti transfer yg ada. Buktinya, PEMBAYARAN UNTUK NOMOR ORDER 112483720 SUDAH DIALKUKAN PADA TGL 19ABRIL DAN BUKTI TRANSFERNYA SAYA LAMPIRKAN JUGA.”

CS : "Mohon maaf atas ketidaknyamanan nya. Kami informasikan bahwa pesanan kamu dengan nomor order 112483720 yang tercancel telah kami buatkan pesanan baru dengan nomor order 1137813900020B. Perihal pembayaran yang telah kamu lakukan telah kami ajukan ke tim finance 
untuk di proses. Mohon kesediaan menunggu prosesnya. Kami mohon maaf atas kesalahan penyampaian atas nama email debora_tina89@yahoo.com dan mohon diabaikan.”

Ujaran ini berada dalam konteks, yakni pelanggan sudah mengirimkan bukti pembayarannya melalui surat elektronik, tetapi ternyata pesanannya batal. Pelanggan juga menerima surat elektronik yang tujuannya atas alamat surat elektronik milik orang lain. Setelah dilakukan kajian, diketahui CS yang menerima surat elektronik dari pelanggan mendapatkan sebuah informasi langsung yaitu pelanggan ingin tetap melanjutkan pemesanannya. Terlihat pada kutipan "tolong dicek baik2 email saya yg dikirim pada tgl 19.04.2018 itu. Bukti pembayarannya saya lampirkan juga disitu dan juga sisa pembayarannya pake BENKAPOINT saya yg ada”. Pelanggan ingin CS tetap melakukan pengecekan dan proses pesanannya. Berdasarkan pemahaman langsung yang diperoleh oleh pekerja layanan pelanggan, implikatur pada percakapan ini termasuk sebagai implicated premises.

\section{Implicated Conclusion}

Data yang menunjuk implicated conclusion sebagai berikut.

\section{Data 02}

Pelanggan : "Dear CS, Saya tidak order barang tersebut untuk kedua kalinya dgn tgl dan jam tersebut, saya sudah transfer untuk pemesanan dengan nomer order 1080881044703. Barang saya sudah terima dan saya kembalikan lagi karena ingin tukar size!"

CS : "Perihal pesanan nomor order $1196801470020 B$ sudah dibatalkan dan untuk retur item pengganti kamu adalah 1160802370030B. Saat ini item tersebut sedang dalam proses approval, mohon menunggu." 
Ujaran 02 berada dalam konteks, pelanggan menerima surel yang berisi tagihan atas pesanan baru yang merasa tidak dipesan. Setelah dilakukan kajian, pelanggan yang menerima jawaban dari CS dapat menyimpulkan sebuah informasi bahwa dia bisa mengabaikan surat elektronik yang berisi tagihan tersebut karena saat ini masih pesanan baru masih dalam menunggu proses persetujuan pembayaran. Namun, pelanggan harus mengaitkan jawaban pekerja layanan pelanggan dengan konteks, karena pekerja layanan pelanggan tidak menjawab secara langsung informasi yang dibutuhkan pelanggan. Untuk itu, implikatur percakapan ini termasuk ke dalam jenis implicated conclusion. Untuk memahami jawaban CS, tidak cukup dengan mengaplikasikan implicated premises.

\section{Pelanggaran Prinsip Kerja Sama}

Pelanggaran terjadi karena terdapatnya ujaran yang tidak memenuhi syarat dari maksim. Objek kajian yang digunakan adalah surel pada periode April 2018 yang berisi data percakapan antara pelanggan dan pekerja layanan pelanggan PT Berrybenka. Pada surel ini ditemukan pelanggaran prinsip kerja sama yang muncul, namun dalam penelitian ini hanya memilih 20 data surat elektronik yang memuat unsur pelanggaran prinsip kerja sama. Data yang digunakan memiliki sumber yang sama dengan data pilihan pada analisis implikatur dan data pada pematuhan prinsip kerja sama, yang dibahas sebelumnya. Penulis membedahnya menurut empat pelanggaran maksim seperti yang dikemukakan oleh Grice.

\section{Pelanggaran Maksim Kuantitas}

Menurut Kushartanti (2005:107) bahwa maksim kuantitas harus memberikan kontribusi yang secukupnya kepada mitra tuturnya. Bahkan maksim kuantitas harus melalui sejumlah syarat, yaitu: Memberikan kontribusi seinformatif mungkin dan apa 
adanya sesuai dengan yang dibutuhkan dan jangan membuat kontribusi lebih dari yang dibutuhkan. Kedua syarat termanifestasi ke dalam data 03.

Data 03

Pelanggan : "Dear CS, Saya tidak order barang tersebut untuk kedua kalinya dgn tgl dan jam tersebut, saya sudah transfer untuk pemesanan dengan nomer order 1080881044703. Barang saya sudah terima dan saya kembalikan lagi karena ingin tukar size!'

CS : "Perihal pesanan nomor order 1196801470020B sudah dibatalkan dan untuk retur item pengganti kamu adalah 1160802370030B. Saat ini item tersebut sedang dalam proses approval, mohon menunggu."

Ujaran data 03 berkonteks, pelanggan menerima surat elektronik yang berisi tagihan atas pesanan baru yang merasa tidak dipesan. Setelah dilakukan kajian, dapat diketahui bahwa pelanggaran prinsip kerja sama telah dilakukan oleh pekerja layanan pelanggan terhadap tuturan yang diucapkannya. Terlihat pekerja layanan pelanggan kurang memberikan informasi. Informasi yang dibutuhkan pelanggan adalah, apakah pemberitahuan yang diterima pelanggan bisa diabaikan atau tidak? Karena pelanggan menerima pemberitahuan melalui surel berisi tagihan. Padahal pelanggan tidak membuat pesanan baru dan terakhir pelanggan hanya melakukan proses retur. Berdasarkan penjabaran tersebut dapat disebutkan pelanggaran yang terjadi adalah pelanggaran maksim kuantitas.

\section{Pelanggaran Maksim Kualitas}

Menurut Kushartanti (2005:107) bahwa maksim kualitas diharuskan kepada peserta percakapan mengatakan hal yang sebenarnya. Seperti diketahui bahwa maksim kualitas diketahui memiliki tiga syarat yaitu: jangan katakan apa yang diyakini kesalahannya, jangan katakan sesuatu yang tidak memiliki bukti yang kuat, 
dan jangan membuat lawan bicara bingung. Menjadi pelanggaran manakala tidak mengikuti ketiga syarat ini. Sebagaimana pada data 04.

\section{Data 04}

Pelanggan : "Tapi Kotor"

CS : "Sebelumnya, mohon maaf atas ketidaknyamanan yang kamu alami. Boleh dibantu informsikan nomor order kamu agar perihal ini dapat kami sampaikan ke tim terkait kami, agar kedepannya tidak terjadi kembali. Dan dapat kami informasikan bahwa, jika barang yang kamu terima di Berrybenka/Hijabenka tidak sesuai atau cacat silahkan lakukan retur dengan syarat dan ketentuan dibawah ini :

1. Kaтu dapat melakukan pengembalian barang dalam jangka waktu 14 hari (termasuk hari libur) terhitung sejak barang kamu terima. Saat kamu menerima barang sudah terhitung sebagai 1 hari.

2. Produk harus dikirimkan dalam kondisi asli dan berada dalam kotak kemasan lengkap dengan aksesoris terkait dan "hang tags".

3. Produk tidak dalam keadaan rusak, kotor, telah dipakai, dan tercelup/terkena air.

4. Kemasan utuh dan tidak rusak, penyok, pecah, sobek, terlipat atau tergores.

5. Harap tidak mengisolasi kotak secara berlebihan tetapi cukup membungkusnya untuk mencegah kerusakan. Barang tersebut tetap menjadi tanggung jawab kamu sampai Berrybenka menerimanya.

6. Mohon bantuan Anda untuk mengembalikan paket dengan hati-hati.

7. Pihak Berrybenka akan melakukan pengecekan kembali akan kualitas produk yang dikembalikan. Apabila ada persyaratan yang tidak dipenuhi, Berrybenka berhak menolak pengembalian produk tersebut. 
8. Untuk pengembalian barang hanya dapat dilakukan dengan memilih salah satu metode pengembalian : - Penukaran barang yang sama (warna/ukuran) - Pengembalian dana (Refund rekening/kredit)

9. Mengisi formulir pengembalian barang dengan lengkap dan benar sesuai dengan petunjuk pengisian.

10.Satu nomor pesanan hanya dapat memilih 1 jenis metode pengembalian (tukar barang/refund/kredit).

11.Perihal ini, apabila kamu sudah melakukan retur mohon mengirimkan bukti resinya agar, biaya ongkir bisa kami gantikan sesuai dengan tarif yang berlaku."

Data 04 memiliki konteks pelanggan sudah menerima pesanan tetapi kondisinya kotor. Setelah dilakukan kajian, dapat diketahui pelanggaran maksim terjadi di tuturan yang diucapkan pelanggan. Hal tersebut terlihat pada kutipan "Tapi kotor". Seharusnya pelanggan memberikan informasi jelas tidak ambigu. Pelanggan seharusnya menguraikan apa yang terjadi dan menguraikan atau menjelaskan informasi apa yang dibutuhkan. Apakah pelanggan membutuhkan informasi terkait syarat untuk retur? Apakah pelanggan membutuhkan informasi untuk alamat pengembalian barangnya? Tetapi, pada tuturan yang diucapkan pelanggan, implikatur yang muncul akan banyak. Hal ini yang menyebabkan tim pekerja layanan pelanggan memberikan semua informasi terkait pengembalian barang. Berdasarkan uraian tersebut, tuturan dapat dimasukan ke dalam pelanggaran maksim kualitas.

\section{Pelanggaran Maksim Relevansi}

Menurut Kushartanti (2005:107) bahwa maksim relevansi mengharuskan setiap peserta percakapan untuk berkontribusi yang relevan dengan situasi pembicaraan. Seperti diketahui bahwa maksim relevansi memiliki dua syarat, yaitu: Mewajibkan setiap penutur memberikan tuturan yang berhubungan atau relevan 
dengan situasi percakapan dan pernyataan dalam tuturan tidak menyimpang dari apa yang sedang dibicarakan. Ketidakpatuhan pada kedua syarat ini menjadi pelanggaran terhadap maksim. Data 05 menjelaskannya.

Data 05

Pelanggan : "Kelamaan sis, barang mau suami saya pakai."

CS : "Dapat kami informasikan kembali untuk pesanan kamu atas nomor order 1512183883224 masih dalam proses pengiriman ulang. Mohon kesediaannya menunggu proses pengiriman ulang pesanan kamu. Terima kasih."

Data 05 memiliki konteks, pesanan pelanggan masih dalam proses pengiriman sebelumnya terkendala pengiriman. Hal ini dapat diketahui bahwa percakapan melalui surat elektronik ini, pelanggaran terjadi pada tuturan yang diucapkan oleh pekerja layanan pelanggan. Pekerja layanan pelanggan tidak mengerti bahwa pelanggan sudah tidak berkenan menunggu karena pesanan sudah ingin digunakan pelanggan, namun pekerja layanan pelanggan menjawab dengan informasi bahwa pesanan masih dalam proses pengiriman. Dilihat dari jawaban pekerja layanan pelanggan, jawaban tidak relevan dengan apa yang dimaksudkan pelanggan, sehingga pelanggaran yang terjadi dapat diklasifikasikan sebagai pelanggaran maksim relevansi.

\section{Pelanggaran Maksim Cara}

Menurut Kushartanti (2005:108) bahwa maksim cara mengharuskan kepada peserta percakapan untuk berbicara langsung dan lugas serta tidak berlebihan. Seperti diketahui bahwa maksim cara memiliki empat syarat utama, yaitu: Menghindari ketidakjelasan pernyataan, menghindari ambiguitas atau kerancuan, ringkas, dan 
berurutan dan rapi. Ketidakpatuhan pada syarat ini dapat berdampak pada pelanggaran maksim cara. Data 06 menjelaskannya.

Data 06

Pelanggan : “OMG!! Kenapa sampai bisa dicancel lagi. Tolong dicek baik2 dulu apakah pembayaran saya itu melebihi batas waktu atau tidak??? Karena setahu saya, pembayarannya saya lakukan tidak melebihi waktu 24 jam. tolong dicek baik2 email saya yg dikirim pada tgl 19.04.2018 itu. Bukti pembayarannya saya lampirkan juga disitu dan juga sisa pembayarannya pake BENKAPOINT saya yg ada. Dan satu hal lagi, email debora_tina89@yahoo.com BUKANLAH EMAIL SAYA! Tolong dicek baik2 ya, saya kecewa untuk ke2 kalinya, karena orderan saya dicancel bukan karena kesalahan saya, tapi kesalahan dari CS Berrybenka yg tidak membalas email kami pada saat mengirim kan bukti transfer yg ada. Buktinya, PEMBAYARAN UNTUK NOMOR ORDER 112483720 SUDAH DIALKUKAN PADA TGL 19ABRIL DAN BUKTI TRANSFERNYA SAYA LAMPIRKAN JUGA."

CS : "Mohon maaf atas ketidaknyamanan nya. Kami informasikan bahwa pesanan kamu dengan nomor order 112483720 yang tercancel telah kami buatkan pesanan baru dengan nomor order $1137813900020 B$. Perihal pembayaran yang telah kamu lakukan telah kami ajukan ke tim finance untuk di proses. Mohon kesediaan menunggu prosesnya. Kami mohon maaf atas kesalahan penyampaian atas nama email debora_tina89@yahoo.com dan mohon diabaikan."

Data 06 memiliki konteks pelanggan sudah mengirimkan bukti pembayarannya melalui surat elektronik, tetapi ternyata pesanannya batal. Pelanggan 
juga menerima surat elektronik yang tujuannya atas alamat surat elektronik milik orang lain. Terhadap hal ini dapat diketahui, walaupun pekerja layanan pelanggan langsung memahami tuturan yang dituturkan pelanggan namun pelanggaran telah melakukan pelanggaran prinsip kerja sama. Hal tersebut dikarenakan pelanggan tidak secara runtut dalam mengemukakan keluhannya. Bahkan keluhannya cenderung bernada berlebihan dari informasi yang seharusnya sudah diketahui oleh CS.

\section{Simpulan}

Surel layanan pelanggan PT Berrybenka pada bulan April 2018 berdampak pada implicated conclusion dan implicated premises. Implicated conclusion terjadi karena di dalam percakapan melalui surat elektronik ternyata membutuhkan analisis lebih lanjut. Banyak praduga yang bisa muncul dari tuturan yang diujarkan, sehingga antara pelanggan dan pekerja layanan pelanggan harus melihat dan mengingat konteks pembicaraan. Di samping itu, surel PT Berrybenka terdapat pula pelanggaran

prinsip kerja sama. Pelanggaran terjadi disebabkan oleh ketidakpatuhan dalam berbahasa antara pelanggan dan petugas PT Berribenka.

\section{Daftar Pustaka}

Fauziah, Mulya Tiara, and Ninuk Lustyantie. 2018. "Pelanggaran Prinsip Kerja Sama Dalam Tuturan Diskusi Kelas Bahasa Indonesia Jurnal Pendidikan Bahasa Dan Sastra Indonesia” 3 (September): 51-57.

Kushartanti. 2005. "Pragmatik" dalam Pesona Bahasa Langkah Awal Memahami Linguistik. Kushartanti, Untung Yowono, Multamia RMT Lauder (Peny.). Jakarta: Gramedia.

Nadar, FX. 2013. Pragmatik dan Penelitian Pragmatik. Yogyakarta: Graha Ilmu. Raco, J.R. 2010. Metode Penelitian Kualitatif, Jenis, Karakteristik, dan Keunggulannya. Jakarta: Grasindo 
Rerung, Rintho Rante. 2018. E-Commerce Menciptakan Daya Saing Melalui Teknologi Informasi. Yogyakarta: Penerbit Deepublish.

Sofia, Hanni dan Budhi Prianto. 2010. Panduan Mahir Akses Internet. Jakarta: Kriya Pustaka.

Wijana, I Dewa Putu dan Muhammad Rohmadi. 2011. Analisis Wacana Pragmatik Kajian Teori dan Analisis. Surakarta: Yuma Pustaka.

Yusuf, Muri. 2017. Metode Penelitian Kuantitatif, Kualitatif \& Penelitian Gabungan. Jakarta: PT Fajar Interpratama Mandiri. 